\title{
Localização, competitividade e tendências da indústria na Amazônia (1996-2010)
}

\section{Location, competition and industry trends in Amazon (1996-2010)}

Maurílio de Abreu Monteiro - Doutor em Desenvolvimento Sustentável do Trópico Úmido pelo NAEA/UFPA. Professor e pesquisador do NAEA/UFPA. E-mail: maurilio_naea@ufpa.br

Adejard Gaia Cruz - Economista, Mestre em Planejamento do Desenvolvimento pelo NAEA/ UFPA. E-mail: adejardgaia@gmail.com

Regiane Paracampos da Silva - Geógrafa, Especialista em Desenvolvimento de Áreas Amazônicas pelo NAEA/UFPA. E-mail: regiane.paracampos@gmail.com

\section{Resumo}

$\mathrm{O}$ artigo dimensiona, caracteriza, diferencia e explicita fundamentos de alterações no padrão de localização e de especialização regional da indústria no Norte do Brasil, entre 1996 e 2010. A partir disso, identifica padrões distintos de expansão industrial: um representado pelo crescimento muito acelerado da indústria extrativa mineral, resultando na redução da diversificação relativa da indústria na região; outro pela expansão moderada de algumas categorias da indústria de transformação. $\mathrm{O}$ artigo indica que tais distinções têm implicações diretas sobre processos de desenvolvimento regional, uma vez que há indícios de que do primeiro padrão expansivo resulta o estabelecimento de relações tênues e facilmente reversíveis entre as estruturas industriais e a sociedade e a economia regionais; já o segundo, aparentemente, impulsiona o fortalecimento de aglomeração urbana que enseja o surgimento de externalidades positivas capazes de impulsionar rendimentos crescentes e processos de desenvolvimento duradouros.

\section{Palavras-chave}

Análise regional. Diferenciação industrial. Desenvolvimento regional. Indústria extrativa. Competitividade.

\begin{abstract}
The article scales, characterizes and differentiates explicit fundamentals of changes in localization pattern, and also regional specialization of industry in the North of Brazil, between 1996 and 2010. Furthermore, it identifies distinct patterns of industrial expansion: one represented by the very rapid growth of mining industry, which results in diversification of industry in the region, and another one represented by moderate expansion of some categories of manufacturing industry. The article indicates that such distinctions have direct implications on regional development processes, since there is evidence that the first expansive pattern is followed by the establishment of relations between tenuous and easily reversible industrial structures and regional economy and society, whereas the second apparently drives the strengthening to urban agglomeration which entails the rising of positive externalities which can drive increasing returns and processes of lasting development.
\end{abstract}

\section{Keywords}

Regional analysis. Industrial differentiation.

Regional development. Mining and quarrying. Competitiveness. 


\section{INTRODUÇÃO}

Entre 1996 e 2010, o Valor da Transformação Industrial (VTI) do Norte Brasil cresceu 127,12\%, muito acima dos 60,29\% de variação do VTI brasileiro. Tal impulso deveu-se, sobretudo, à ampliação do VTI do estado do Pará que, no período, foi multiplicado por 4,8, em função do crescimento da indústria extrativa. Já no estado do Amazonas, o crescimento do VTI foi de 42,33\%, situando-se abaixo da média nacional. Ele foi baseado, sobretudo, na expansão da fabricação de produtos alimentícios, bebidas e produtos do fumo, especialmente a de bebidas; e da fabricação de outros equipamentos de transporte, principalmente da fabricação de motocicletas, bicicletas e triciclos duas rodas. Este descompasso entre ritmos de crescimento permitiu que o Pará suplantasse, em VTI, o Amazonas que, em 1996, tinha VTI 3,3 vezes maior do que o do Pará.

As estruturas industriais desses dois estados são amplamente responsáveis pela configuração do perfil da indústria no Norte, uma vez que eles respondem por $93,24 \%$ do VTI da região, cabendo, assim, parcela pouco significativa aos cinco demais estados. Todavia, evidenciaram-se, nos dois padrões muito distintos de expansão industrial, diferenciações que podem guardar implicações diretas com os rumos dos processos de desenvolvimento em cada um desses estados, uma vez que a literatura que analisa os desdobramentos da produção industrial sobre dinâmicas sociais e econômicas da região aponta, por um lado, que a indústria extrativa não mobilizou "elementos determinantes para o estabelecimento de vantagens competitivas que impulsionem processos de desenvolvimento socialmente enraizados" (MONTEIRO, 2005, p. 198), assumindo, assim, um caráter enclávico, na medida em que estabelece relações muito frágeis com a sociedade e a economia regionais (COELHO, MONTEIRO, 2005; MONTEIRO, 2003; BUNKER, 2000, 2004; SILVA, 1998); por outro, estudos que analisam as dinâmicas sociais e econômicas impulsionadas pela indústria de transformação no Amazonas apontam que o crescimento dessa indústria tem contribuído regionalmente para a formação de aglomerações produtivas, das quais resultam de externalidades positivas (OLIVEIRA JUNIOR et al., 2006; GARCIA, 2004; OLIVEIRA JÚNIOR, MACHADO, 2009).

Neste contexto, o artigo dimensiona, caracteriza, diferencia e explicita os fundamentos desse movimento de concentração e de especialização da atividade industrial no Norte do Brasil. Para tanto, foram produzidos indicadores estaduais 
de especialização, de concentração e de competitividade para categorias de indústria.

Para expressar os resultados da pesquisa, o trabalho está organizado em seis seções, além desta introdução. A segunda descreve os procedimentos metodológicos, as bases de dados utilizadas e o tratamento estatístico dado às informações. A apresentação e a análise dos índices de concentração e de especialização da indústria na região Norte integram a terceira seção. A quarta seção traz a caracterização e o desempenho recente da indústria regional. A quinta seção apresenta os indicadores de competitividade regional. A última seção traz a discussão dos resultados e os comentários finais.

\section{METODOLOGIA E BASE DE DADOS}

\subsection{CLASSIFICAÇÃO DA INDÚSTRIA E BASES DE DADOS UTILIZADAS}

Inicialmente foi realizada a harmonização das bases de dados usadas no estudo. Isso em razão da revisão promovida na estrutura da Classificação Nacional de Atividades Econômicas (CNAE) que resultou em nova versão, a CNAE 2.0, que passou a vigorar a partir de 2006.

Até 2007 a PIA-Empresa era divulgada na versão 1.0 da CNAE, mas a partir do ano de referência 2008, com resultados relativos a 2007, o IBGE passou a divulgar a pesquisa utilizando a versão 2.0 da CNAE. No caso da RAIS, a divulgação dos dados pelo Ministério do Trabalho e Emprego (MTE) na versão 2.0 da CNAE passou a vigorar a partir do ano de referência 2006.

Para obter uma série histórica coerente foi estabelecida correspondência no nível de divisão (a 2 dígitos) entre a CNAE 1.0 e a CNAE 2.0, abrangendo dois setores: indústria extrativa e indústria de transformação. Em seguida, realizou-se agregação entre algumas divisões. Tal compatibilização resultou no agrupamento em 17 categorias de indústria (Quadro 1), tendo como critério de classificação a semelhança entre as atividades (correspondência direta) e a proximidade das características (correspondência indireta). 
114 Maurilio de Abreu Monteiro $\bullet$ Adejard Gaia Cruz $\bullet$ Regiane Paracampos da Silva

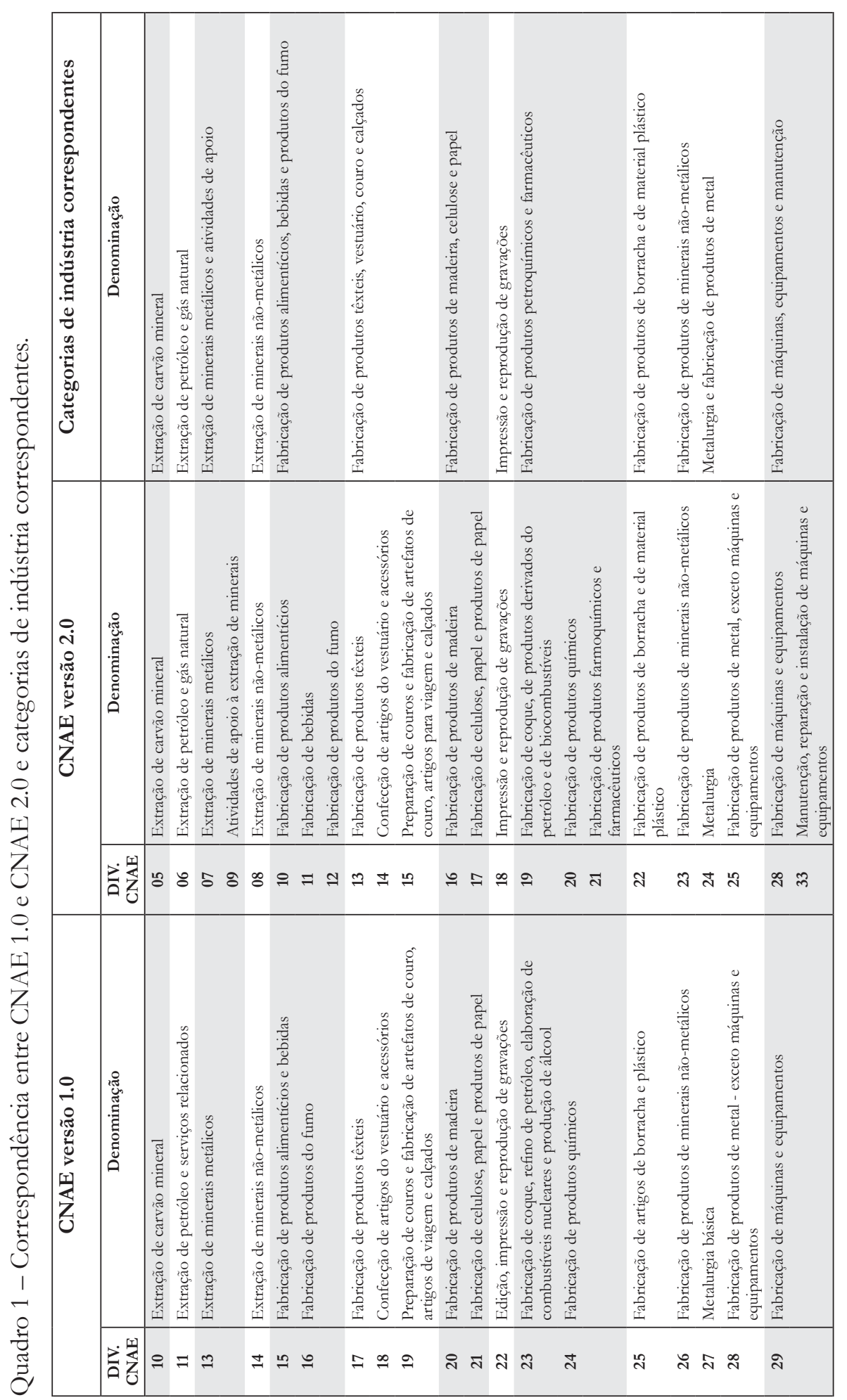

Novos Cadernos NAEA • v. 15 n. 2 • p. 111-141 • dez. 2012 


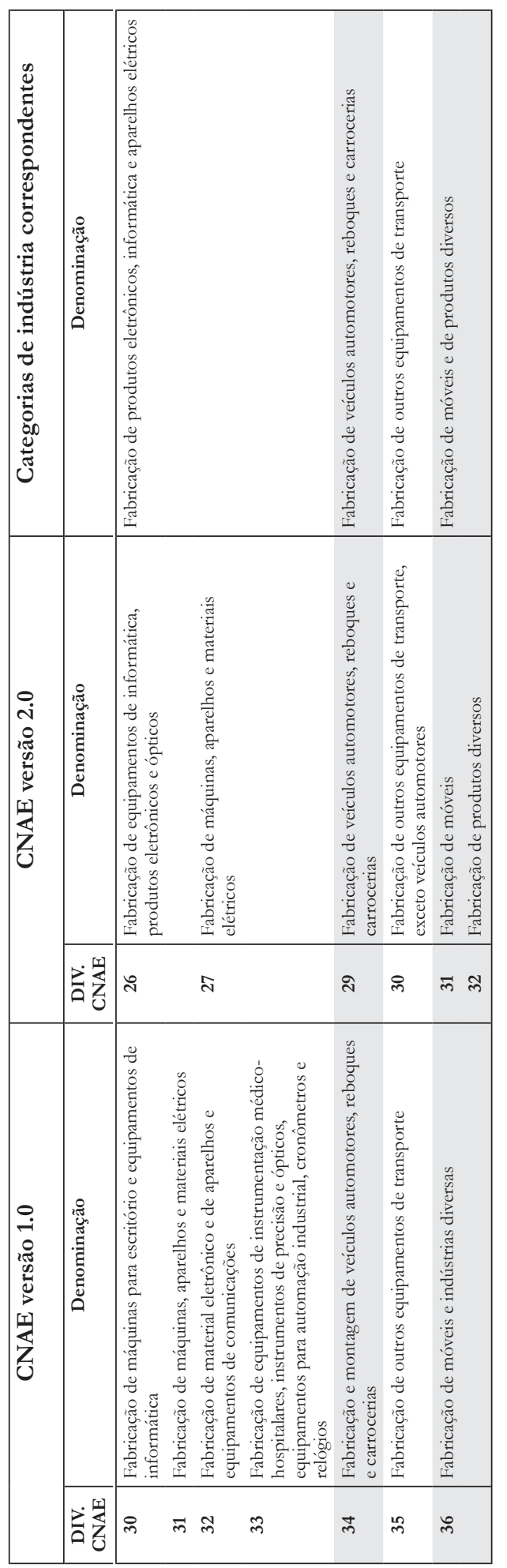

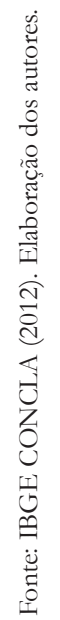

Novos Cadernos NAEA • v. 15 n. 2 • p. 111-141 • dez. 2012 
Estabelecida a segmentação em 17 categorias de indústria e adotandose como unidade espacial os estados e o Distrito Federal, escolheu-se o VTI fornecido pela Pesquisa Industrial Anual Empresa (PIA - Empresa) como proxy para efetuar o rateio do valor adicionado industrial visando aos recortes mencionados. A escolha do VTI deveu-se, em especial, pelo fato de ele ser indicador capaz de captar as variações de produtividade do trabalho industrial, que se alterou significativamente a partir dos anos 1990 (SALM, SABOIA, CARVALHO, 1997; ROSSI, FERREIRA, 1999). No que se refere ao recorte temporal, optou-se por adotar como marco inicial de análise o ano de 1996, uma vez que, a partir dele, a PIA foi adequada aos parâmetros do novo modelo de elaboração das estatísticas industriais, e que os censos econômicos quinquenais foram substituídos por pesquisas anuais de base amostral (IBGE, 2004).

A PIA-Empresa levanta informações econômico-financeiras das empresas industriais e de suas unidades locais, isso porque a pesquisa está organizada por unidades múltiplas com identificação das unidades locais, tendo a empresa como unidade central de investigação e núcleo em torno do qual se articulam estas unidades locais, permitindo, assim, que sejam captadas dinâmicas regionais, uma vez que, mesmo estando a sede da empresa localizada noutra unidade espacial, o valor da transformação industrial será computado naquela unidade onde efetivamente ocorreu. Isso se dá porque as estatísticas no nível das unidades locais são construídas por rateio das informações no nível da empresa, tomando por parâmetro as variáveis informadas no nível local, razão pela qual se optou por utilizar as informações das unidades locais.

A PIA-Empresa também adota dois estratos para a efetivação da pesquisa: o estrato certo e o aleatório. O estrato certo compreende o levantamento censitário das empresas com 30 ou mais pessoas ocupadas; e o estrato aleatório envolve as empresas com 5 a 29 pessoas ocupadas, selecionadas aleatoriamente sem reposição. Como a divulgação de resultados para a região Norte é feita no nível de divisão, 2 dígitos da CNAE, optou-se por se utilizar, neste trabalho, as estatísticas de empresas industriais com 5 ou mais pessoas ocupadas ao nível de divisão.

O VTI e demais variáveis utilizadas para o cálculo dos indicadores tiveram seus valores deflacionados pelo Índice Geral de Preços - Disponibilidade Interna (IGP-DI), medido pela Fundação Getúlio Vargas. 


\subsection{OS INDICADORES UTILIZADOS}

O desenvolvimento dos cálculos envolveu o manejo de inputs numéricos tomados de diversas variáveis, a VTI, principal delas, é indicada, genericamente, como $x$. Para produzir os indicadores de especialização, de concentração e de competitividade das 17 categorias de indústria das quais se dispõem dos valores observados, desagregados por 27 unidades da federação, designando-se por:

$k=1, \ldots, k, \ldots, K$ cada um das 17 categorias de indústria indicadas no Quadro 1;

$i=1, \ldots, i . \ldots, I$, cada uma das 27 unidades territoriais (estados e Distrito Federal) em que se divide o espaço de análise; e

$x_{i k}=$ o valor do VTI para a unidade territorial $i$ e a categoria de indústria k.

$x_{k}=\sum_{i=1}^{I} x_{i k} \quad$, valor total da variável $x$ para a categoria de indústria $k ;$
$x_{i}=\sum_{k=1}^{K} x_{i k} \quad$, valor total da variável $x$ na unidade da federação $i ;$
$x=\sum_{i=1}^{I} \sum_{k=1}^{K} x_{i k} \begin{aligned} & \text { todas as } K \text { categorias de indústria e todas as } I \text { unidades } \\ & \text { espaciais. }\end{aligned}$

As demais variáveis seguem o mesmo critério de agregação por unidades da federação e por categorias de indústria, tendo os aspectos específicos de sua notação expressa nos itens seguintes.

\subsubsection{Medidas de especialização e reestruturação industrial}

Para as 27 unidades da federação foram calculados indicadores de especialização (Coeficiente de Especialização) e reestruturação (Coeficiente de Reestruturação), a partir do V'TI.

O Coeficiente de Especialização (CE) (DUNCAN, DUNCAN, 1955; ISARD, 1960; HOOVER, GIARRATANI, 1984; HADDAD, 1989) é obtido comparando a distribuição por categoria de indústria do VTI na unidade 
territorial $i$ com a distribuição por categoria do VTI no espaço de referência. A formalização matemática é dada por 1:

(1) $C E_{i}=\frac{1}{2} \sum_{k=1}^{K}\left|\frac{x_{i k}}{x_{i}}-\frac{x_{k}}{x}\right|$

O indicador de evolução temporal (1996 e 2010) das características de especialização de uma unidade espacial será o Coeficiente de Reestruturação $C R_{i}$ (ISARD, 1960, p. 275) construído tendo por base a equação 2:

(2) $C R_{i}=\frac{1}{2} \sum_{k=1}^{K}\left[\left\|\left(\frac{x_{i k}}{x_{i}}\right)_{t 1}-\left(\frac{x_{i k}}{x_{i}}\right)_{t 0}\right\|\right]$

\subsubsection{Medidas de tendência}

Para indicar as diferenciadas tendências existentes entre as categorias de indústria nos estados será realizado o cálculo do Viés Característico da Indústria (VCI). Este indicador permite avaliar a tendência, ou seja, o viés de dada categoria de indústria em determinada unidade territorial (MIDELFART-KNARVIK, 2000, p. 13). Utilizando o VTI como variável de análise do nível de atividade da indústria de um determinado estado, em um dado período de tempo, e assumindo a existência de um conjunto de características dessa indústria, o VCI pode ser descrito através de 3:

$$
V C I_{i}=V_{i k} \cdot Z_{i k}
$$

Onde,

$$
\text { (4) } \quad V_{i k}=\frac{x_{i k}}{\sum_{k} x_{i k}}
$$

Sendo que $V_{i k}$ é o valor do VTI da categoria de indústria $k$, em dada unidade espacial, dividido pelo valor total do VTI da indústria do estado $i$, em um dado instante; e que $Z_{i k}$ é o valor médio de dada característica, na categoria de indústria $k$, em uma unidade espacial. Ou seja, cada característica da indústria é ponderada pela participação dessa indústria no VTI total do estado ou do Novos Cadernos NAEA • v. 15 n. 2 • p. 111-141 • dez. 2012 
distrito federal $\left(x_{i}\right)$. Com base nos dados da PIA-Empresa, foram selecionadas quatro características da indústria, a seguir descritas, para construção dos $Z_{k}$ correspondentes. Estas características são:

a) Intensidade da remuneração média: razão entre a variável "Salários, Retiradas e outras Remunerações" ( $S R R)$ e a "Pessoal Ocupado" (PO). Mede a qualidade da força de trabalho empregada na produção, uma vez que maiores remunerações estão geralmente associadas a uma maior especialização e qualificação da força de trabalho. A formalização matemática do cálculo do valor médio dessa característica é dada por 5:

$$
Z_{k a}=\frac{S R R_{i k}}{P O_{i k}}
$$

b) Participação do trabalho: sendo proporção dos "Salários, Retiradas e outras Remunerações" (SRR) no VTI $(x)$, pode ser entendida como medida de produtividade do trabalho. Quanto menor este indicador, maior a produtividade da força de trabalho. Formalmente, $Z_{k b}$ é dado por 6:

$$
Z_{k b}=\frac{S R R_{i k}}{x_{i k}}
$$

c) Economia de escala: razão entre "Custo das Operações Industriais" (COI) e o "Valor Bruto da Produção Industrial" (VBPI). Quanto menor o indicador, maior a economia de escala. Assim, $Z_{k c}$ é calculado tendo por base a equação 7:

$$
\text { (7) } \quad Z_{k c}=\frac{C O I_{i k}}{V B P I_{i k}}
$$

d) Intensidade de intermediários: grau de utilização do "Consumo Matérias-Primas, materiais auxiliares e componentes" (CMP) sobre o "Valor Bruto da Produção Industrial" (VBPI). Mede a eficiência produtiva. Quanto menor este indicador, maior é a eficiência do processo produtivo. A formalização matemática do cálculo do valor médio da Intensidade de intermediários é dada por 8: 
(8) $\quad Z_{k d}=\frac{C M P_{i k}}{V B P I_{i k}}$

\subsubsection{Medida de competitividade industrial}

Para medir o nível de competitividade da indústria regional em relação à economia nacional, foi utilizado o Índice de Custo Relativo (ICUR), que capta a competitividade potencial relativa de cada categoria industrial do estado em relação à economia nacional (SILVA, ALVES, 2010; GONÇALVES et al., 2003). A expressão matemática do ICUR é dada por 9:

(9) IICUR $=\frac{\frac{Y_{i k}}{P_{i k}}}{\frac{Y_{k}}{P_{k}}}$

Sendo $Y_{i k}$, o custo unitário da força de trabalho de uma das 17 categorias de indústria, $k$, em dada unidade espacial, $i$. É calculado pela equação 10 :

(10) $\quad Y_{i k}=\frac{S R R_{i k}+E I B_{i k}}{P O_{i k}}$

Onde: EIB representa a variável "Encargos, Indenizações e Benefícios" e SSR equivale a variável "Salários, Retiradas e outras Remunerações", como indicado anteriormente.

A expressão $P_{\mathrm{ik}}$ representa a produtividade da força de trabalho, de determinada categoria de indústria, em dada unidade espacial, $i$. É calculada pela equação 11:

$$
P_{i k}=\frac{x_{i k}}{P O_{i k}}
$$

Logo, em conformidade com a notação adotada, $Y_{k}$ e $P_{k}$ representam, em termos nacionais, o custo unitário da força de trabalho de uma das $k$ categorias de indústria; e a produtividade da força de trabalho de uma das k categorias de indústria, respectivamente. 
O ICUR viabiliza, assim, a comparação de uma unidade espacial com uma área de referência e sua maior ou menor competitividade potencial relativa pode ser decorrente de menores custos unitários da mão de obra, de maior produtividade dessa mesma mão de obra ou de combinações favoráveis desses dois fatores.

Um ICUR maior que a unidade revela que os custos do trabalho superam os ganhos de produtividade, indicando perda de competitividade de uma categoria, $k$, de um determinado estado, $i$, em relação ao Brasil, e vice-versa, quando o índice é menor do que a unidade.

Nesse sentido, os indicadores de cada fator competitivo são analisados em conjunto com o ICUR, permitindo estabelecer uma relação que expresse competitividade potencial relativa resultante da estrutura, eficiência e desempenho das categorias industriais investigados.

$\mathrm{Na}$ análise do VCI e do ICUR, também foram utilizados alguns indicadores de eficiência, desempenho e capacitação, baseados nas formulações de Possas (1977) e Coutinho e Ferraz (1994).

\section{CONCENTRAÇÃO E ESPECIALIZAÇÃO DA INDÚSTRIA NA REGIÃO NORTE}

Para se inferir o grau de diversificação regional da produção industrial nos anos 1996 e 2010, são apresentados os valores do $C E_{i}$, que aponta o quão são especializados, ou seja, o quão são distintos os estados e o Distrito Federal em relação à indústria nacional. Trata-se, entretanto, de análise com elevado nível de agregação, quer seja das unidades espaciais, quer seja das categorias de indústria (Quadro 2).

As estatísticas de dispersão relativas aos valores do $C E_{i}$ evidenciam um quadro de estabilidade nos padrões de diversificação regional da indústria ao longo do período analisado. Essa estabilidade da especialização relativa da indústria nos estados é expressa pela média e pela mediana dos valores do $C E_{i}$ de 2010, quase idênticos aos de 1996. As estatísticas de assimetria dos índices de especialização regional podem ser interpretadas como níveis de dispersão em relação à média de uma série. Tanto, em 1996, quanto, em 2010, houve grande concentração de valores do $C E_{i}$ entre 0,45 e 0,60 . Nesse intervalo foram 
registrados $C E_{i}$ atribuídos a 11 unidades espaciais que guardam grande distância dos valores $C E_{i}$ registrados pelas unidade mais próximas ao extremo da série, as menos especializadas. Assim, ao se comparar os resultados de 1996 e de 2010 se observa a relativa manutenção da assimetria, mesmo quando se leva em conta que, em 1996, tenha sido registrada uma distribuição negativa, com assimetria para a direita em relação à média da série; e que, em 2010, tenha sido registrada uma distribuição positiva com assimetria para a esquerda em relação à média da série (Quadro 2).

Quadro 2 - Estatísticas descritivas de índices de especialização industrial para unidades da federação para os anos de 1996 e 2010.

\begin{tabular}{|l|c|c|}
\hline \multicolumn{1}{|c|}{ Estatísticas descritivas } & $C E_{i} 2010$ & $C E_{i} 1996$ \\
\hline Média & 0,4600 & 0,4581 \\
\hline Erro padrão & 0,0338 & 0,0306 \\
\hline Mediana & 0,4759 & 0,4680 \\
\hline Desvio padrão & 0,1757 & 0,1588 \\
\hline Curtose & $-0,5009$ & $-0,1717$ \\
\hline Assimetria & 0,1556 & $-0,1404$ \\
\hline Intervalo & 0,6666 & 0,6783 \\
\hline Mínimo & 0,1552 & 0,1213 \\
\hline Máximo & 0,8218 & 0,7996 \\
\hline
\end{tabular}

Fonte: Elaboração dos autores por meio do tratamento estatístico de dados da PIAempresa (1996 e 2010).

O Quadro 3 apresenta resultados dos indicadores de diversificação e reestruturação espacial da atividade industrial para os estados brasileiros, enquanto a expressão cartográfica desses índices é apresentada na Figura 1. A primeira coluna foi ordenada pelos escores crescentes do $C E_{i}$ de 2010 e expressa, por conseguinte, uma medida hierarquizada da proximidade ou da divergência dos dois padrões de especialização (diversificação) industrial, permitindo avaliar o nível de especialização relativa de cada uma das 27 unidades da federação em relação ao nível de diversificação do espaço nacional brasileiro (Quadro 3) (Figura 1).

A escala do $C E_{i}$ varia entre 0 e 1 , em que o valor zero equivale a inexistência de especialização relativa da unidade espacial em relação ao espaço brasileiro, ou seja, a unidade da federação é totalmente diversificada; e o valor 1 
representa situação inversa, em que a estrutura industrial da unidade da federação é mais especializada. Em suma, quanto mais elevado o valor do $C E_{i}$, tanto mais o padrão de especialização industrial da unidade espacial se afasta do conjunto do espaço nacional, correspondendo à estrutura industrial pouco diversificada (Figura 1).

Quadro 3 - Indicadores de diversificação e de reestruturação espacial da atividade industrial nas unidades da federação, entre 1996 e 2010, tendo por base o VTI.

\begin{tabular}{|l|c|c|c|c|c|}
\hline \multicolumn{1}{|c|}{$\begin{array}{c}\text { Unidades da } \\
\text { Federação }\end{array}$} & $C_{i} 2010$ & $\begin{array}{c}\text { Ordem } \\
C E_{i} 2010\end{array}$ & $C E_{i} 1996$ & $\begin{array}{c}\text { Ordem } \\
C E_{i} 1996\end{array}$ & $C_{i}$ \\
\hline São Paulo & 0,1552 & 1 & 0,1213 & 1 & 0,1083 \\
\hline Paraná & 0,1921 & 2 & 0,2468 & 3 & 0,2384 \\
\hline Rio Grande do Sul & 0,2070 & 3 & 0,2121 & 2 & 0,1666 \\
\hline Goiás & 0,2622 & 4 & 0,3689 & 9 & 0,1870 \\
\hline Bahia & 0,2671 & 5 & 0,3649 & 8 & 0,1747 \\
\hline Minas Gerais & 0,2712 & 6 & 0,3075 & 6 & 0,1868 \\
\hline Pernambuco & 0,3293 & 7 & 0,2627 & 5 & 0,1429 \\
\hline Santa Catarina & 0,3342 & 8 & 0,3470 & 7 & 0,1506 \\
\hline Rio de Janeiro & 0,3621 & 9 & 0,2533 & 4 & 0,4481 \\
\hline Mato Grosso do Sul & 0,3767 & 10 & 0,5290 & 18 & 0,2824 \\
\hline Rio Grande do Norte & 0,4194 & 11 & 0,5893 & 22 & 0,3466 \\
\hline Ceará & 0,4288 & 12 & 0,4525 & 13 & 0,1329 \\
\hline Maranhão & 0,4718 & 13 & 0,4524 & 12 & 0,4038 \\
\hline Sergipe & 0,4759 & 14 & 0,5731 & 21 & 0,3969 \\
\hline Tocantins & 0,4889 & 15 & 0,5901 & 23 & 0,3404 \\
\hline Paraíba & 0,5294 & 16 & 0,4350 & 10 & 0,1249 \\
\hline Mato Grosso & 0,5296 & 17 & 0,4824 & 15 & 0,2175 \\
\hline Alagoas & 0,5391 & 18 & 0,5585 & 19 & 0,3637 \\
\hline Espírito Santo & 0,5395 & 19 & 0,4680 & 14 & 0,3218 \\
\hline Amazonas & 0,5423 & 20 & 0,4454 & 11 & 0,2088 \\
\hline Distrito Federal & 0,5509 & 21 & 0,4928 & 16 & 0,3129 \\
\hline Piauí & 0,5642 & 22 & 0,5261 & 17 & 0,2755 \\
\hline Rondônia & 0,5910 & 23 & 0,6075 & 25 & 0,5039 \\
\hline Pará & 0,6982 & 24 & 0,5675 & 20 & 0,4683 \\
\hline Roraima & 0,7020 & 25 & 0,6047 & 24 & 0,1836 \\
\hline Amapá & 0,7715 & 26 & 0,7092 & 26 & 0,3595 \\
\hline Acre & 0,8218 & 27 & 0,7996 & 27 & 0,2953 \\
\hline
\end{tabular}

Fonte: Elaboração dos autores por meio do tratamento estatístico de dados da PIAEmpresa (1996 e 2010). 
Figura 1 - Mapa de diversificação espacial da atividade industrial em unidades da federação (CE), baseado no VTI (1996 e 2010).
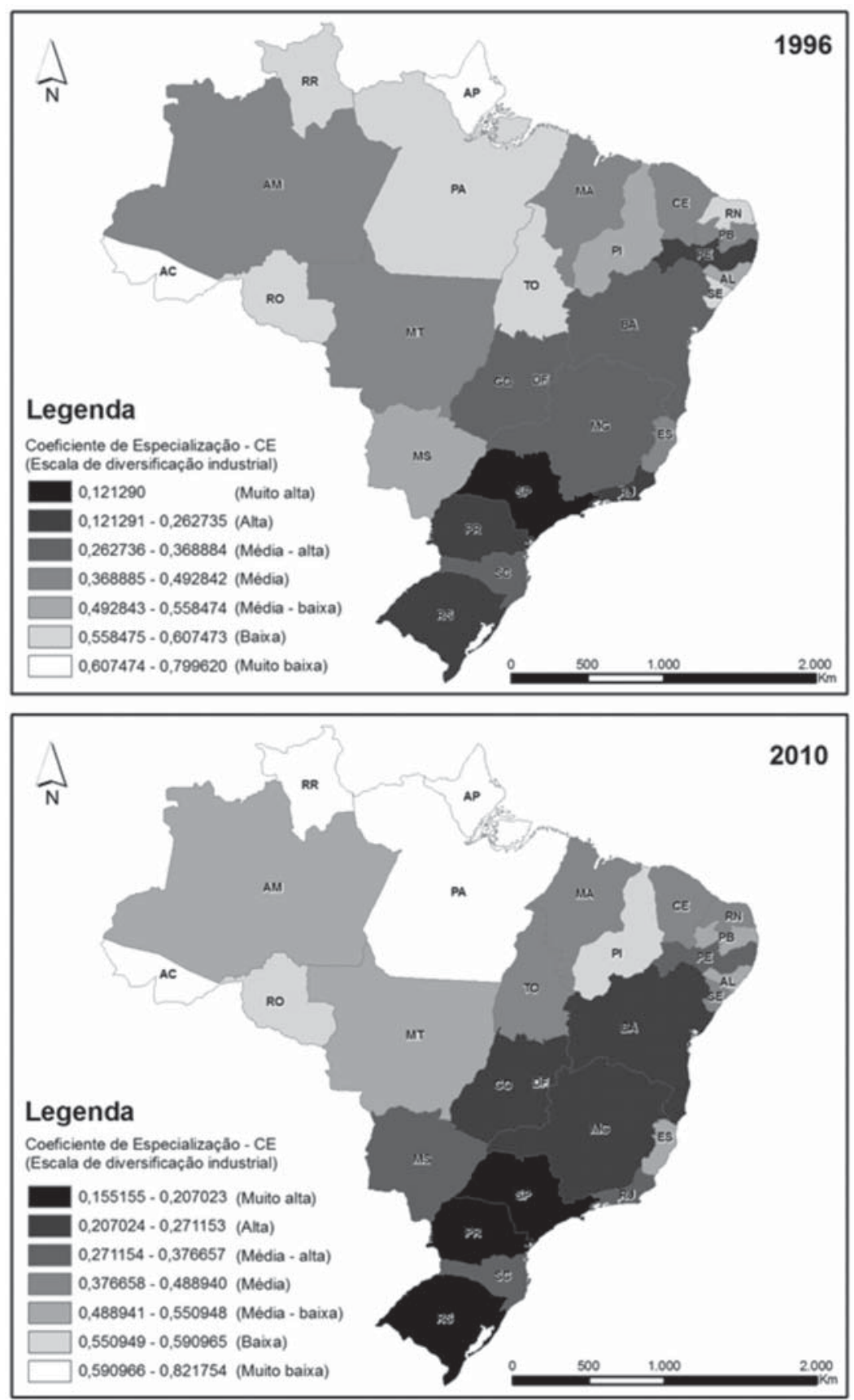

Fonte: Elaboração dos autores por meio do tratamento estatístico de dados da PIAEmpresa (1996 e 2010). Base Cartográfica IBGE, 2010. 
É importante entender que o $\mathrm{CE}_{i}$ é uma medida relativa de especialização. Valores baixos relacionados à estrutura industrial da unidade da federação não implicam, necessariamente, a diversificação absoluta desta estrutura, mas, sobretudo, o grau de proximidade entre os perfis de especialização dessa unidade da federação e o Brasil. Assim, pelo fato de duas unidades da federação - como o Pará (0,5675) e Rondônia (0,6075) - apresentarem, em 1996, valores de CE $\mathrm{E}_{i}$ quase idênticos, não se poderá daí inferir que haja a mesma combinação em relação à proporção entre dadas categorias de indústria em seus territórios, mas, tãosomente, que possuem o mesmo padrão de especialização (diversificação) das suas estruturas industriais, podendo envolver tipos diferentes de indústria (Quadro 3).

Em 1996, o Amazonas era o estado que apresentava o $C E_{i}$ indicativo de maior diversificação industrial na região Norte; o Pará $(0,5675)$ e o Tocantins $(0,5901)$ ocupavam posição intermediária; e os estados de Roraima $(0,6047)$, de Rondônia (0,6075), do Amapá (0,7092) e do Acre (0,7996) obtiveram, respectivamente, os índices que indicavam a mais elevada especialização, tanto em nível nacional quanto regional. Em 2010, registrou-se a ampliação da especialização da estrutura industrial do Pará, o que se deveu diretamente ao grande incremento da extração de minerais metálicos que, em termos relativos, tornou a produção industrial regional mais homogênea, menos diversa (Quadro 3) (Figura 1).

Ao se confrontar os $C E_{i}$ de dois anos distintos, estar-se-á produzindo o $C E_{i}$, como descrito anteriormente. Este índice relaciona a estrutura industrial na unidade espacial $i$ entre dois períodos, a fim de avaliar o grau de mudança na especialização desta unidade espacial. Os valores desse coeficiente variam entre zero e um. Quanto mais próximo da unidade for o resultado, maiores serão os indícios de alterações na estrutura de categorias do estado; e quanto mais o $C R_{i}$ se aproxima de zero maiores serão os indícios de que não houve modificação na composição de categorias de indústria do estado.

No período analisado, o $C E_{i}$ traz forte indicação de que as alterações ocorridas na estrutura industrial dos estados do Norte foram diferenciadas no intervalo de tempo em questão (Quadro 3). Em Roraima (0,1836) e no Amazonas $(0,2088)$, registraram-se movimentos muito discretos de modificação estrutural na indústria; já no Acre (0,2953), no Tocantins (0,3404) e no Amapá (0,3595), houve movimentos ligeiramente mais acentuados; enquanto o Pará $(0,4683)$ e Rondônia (0,5039) registraram as maiores mudanças (Quadro 3). Essas mudanças se devem à combinação de resultados, mas no Pará elas ocorreram, sobretudo, pela superioridade do ritmo de expansão da extração de minerais metálicos e atividades 
de apoio em relação ao das demais categorias; em Rondônia, as mudanças devemse, em especial, ao crescimento acelerado da fabricação de produtos alimentícios, bebidas e fumo; e da fabricação de produtos de minerais não metálicos.

\section{CARACTERIZAÇÃO E DESEMPENHO RECENTE DA INDÚSTRIA REGIONAL}

Entre 1996 e 2010, o VTI cresceu nas regiões Norte (de 4,53\% para 6,42\%), Nordeste (de 7,63\% para 9,20\%), Centro-Oeste (de 2,25\% para 4,48\%) e Sul (de $17,27 \%$ para $18,41 \%$ ), ao passo que a região Sudeste declinou de 68,32\% para 61,49\% em 2010 (Quadro 4). Tais dados, grosso modo, retratam tendência de desconcentração industrial no Brasil. Eles correspondem à expectativa inicial da pesquisa e apontam a manutenção de um processo de desconcentração industrial iniciado entre 1970 e 1991 (LEMOS, SANTOS, CROCCO, 2005; DINIZ, 1993) e que se manteve de forma menos intensa nos anos 1990 (SABOIA, 2001; AZEVEDO, TONEDO JÚNIOR, 2001).

Quadro 4 - Participação das grandes regiões e unidades da federação selecionadas no número de Unidades Industriais Locais, Pessoal Ocupado e Valor da Transformação Industrial (1996 e 2010).

\begin{tabular}{|l|r|r|r|r|r|r|}
\hline Grandes Regiões & \multicolumn{3}{|c|}{1996} & \multicolumn{3}{c|}{2010} \\
\cline { 2 - 7 } $\begin{array}{c}\text { e Unidades da } \\
\text { Federação }\end{array}$ & $\%$ UL & \% PO & \% VTI & \% UL & $\%$ PO & \% VTI \\
\hline Brasil & 100,00 & 100,00 & 100,00 & 100,00 & 100,00 & 100,00 \\
\hline Norte & 2,35 & 2,63 & 4,53 & 2,80 & 3,38 & 6,42 \\
\hline Rondônia & 0,46 & 0,27 & 0,07 & 0,60 & 0,35 & 0,26 \\
\hline Acre & 0,08 & 0,03 & 0,01 & 0,12 & 0,07 & 0,03 \\
\hline Amazonas & 0,51 & 1,17 & 3,36 & 0,59 & 1,48 & 2,99 \\
\hline Roraima & 0,04 & 0,01 & 0,00 & 0,05 & 0,02 & 0,01 \\
\hline Pará & 1,09 & 1,05 & 1,00 & 1,08 & 1,24 & 3,00 \\
\hline Amapá & 0,06 & 0,04 & 0,06 & 0,09 & 0,05 & 0,07 \\
\hline Tocantins & 0,11 & 0,05 & 0,02 & 0,27 & 0,16 & 0,07 \\
\hline Nordeste & 9,18 & 10,47 & 7,63 & 11,80 & 13,12 & 9,20 \\
\hline Sudeste & 60,78 & 61,06 & 68,32 & 50,72 & 53,26 & 61,49 \\
\hline Sul & 23,27 & 22,73 & 17,27 & 28,36 & 24,99 & 18,41 \\
\hline Centro-Oeste & 4,43 & 3,11 & 2,25 & 6,32 & 5,26 & 4,48 \\
\hline
\end{tabular}

Fonte: IBGE, Pesquisa Industrial Anual (PIA), 1996 e 2010. Elaboração dos autores.

Novos Cadernos NAEA • v. 15 n. 2 • p. 111-141 • dez. 2012 
A desagregação do crescimento do VTI por estados da região Norte, entre 1996 e 2010, revela que o Pará obteve o crescimento do VTI mais relevante. $\mathrm{E}$, em que pese este grande aumento do VTI, a participação relativa do estado em termos de unidades industriais locais e de pessoal ocupado permaneceu praticamente estável ao passo que sua participação relativa no VTI triplicou no mesmo período, aumentando de 1,09\% para 3\%, expressando, em termos gerais, o segundo maior aumento de produtividade do trabalho dentre os estados brasileiros $(158,77 \%)$, o que se vinculou ao crescimento da produtividade do trabalho na extração industrial de minerais metálicos (minérios de ferro, de cobre de alumínio e de manganês). Registrando tendências diferenciadas, o estado do Amazonas aumentou o nível de pessoal ocupado e do número de unidades industriais, porém apresentou queda na participação no VTI da indústria nacional, oscilando de 3,36\% para 2,99\% (Quadro 4).

Ao se realizar a desagregação do comportamento do VTI por categoria da indústria, revela-se que, no período, a extração de minerais metálicos multiplicou o seu VTI por mais de dez vezes, implicando a ampliação de 7,45\% para 36,97\% da participação dessa categoria no total do VTI regional, desempenho impulsionado pelo atendimento à crescente demanda internacional de minérios (Quadro 5).

A avaliação desagregada, por categoria de indústria, permite indicar, também, que foi muito expressiva a retração da fabricação de produtos de madeira, celulose e papel, que teve sua expressão relativa regional reduzida em quase um quarto (de 7,48\% para 2,53\%). Esta categoria foi a que mais perdeu empregos no período, além de reduzir sua participação no número de unidades industriais. A categoria já vinha enfrentando dificuldades desde 2004 por conta da elevação dos custos operacionais e da valorização do real frente ao dólar. Entre 2008 e 2009 a fabricação de produtos de madeira sofreu forte abalo por conta da crise financeira e econômica mundial que resultou na redução de mercado. Nesta categoria houve redução no valor médio da remuneração $(-11,7 \%)$ e no valor da transformação industrial (-23,28\%). 
Quadro 5 - Participação das categorias de indústrias no Valor da Transformação Industrial, região Norte, 1996 e 2010.

\begin{tabular}{|c|c|c|c|c|c|}
\hline \multirow[b]{2}{*}{ Categorias de Indústrias } & \multicolumn{2}{|c|}{1996} & \multicolumn{2}{|c|}{2010} & \multirow{2}{*}{$\begin{array}{c}\text { Var. Rel. } \\
\%\end{array}$} \\
\hline & VTI & $\begin{array}{c}\text { Part. } \\
\%\end{array}$ & VTI & $\begin{array}{c}\text { Part. } \\
\%\end{array}$ & \\
\hline Indústria Geral & 25.525 .587 & 100,00 & 57.973 .581 & 100,00 & 127,12 \\
\hline Indústrias de transformação & 23.615 .385 & 92,52 & 36.516 .180 & 62,99 & 54,63 \\
\hline Indústrias extrativas & 1.910 .202 & 7,48 & 21.457 .401 & 37,01 & $1.023,31$ \\
\hline $\begin{array}{l}\text { Extração de minerais metálicos } \\
\text { e ativ. de apoio }\end{array}$ & 1.901 .809 & 7,45 & 21.432 .313 & 36,97 & $1.026,94$ \\
\hline $\begin{array}{l}\text { Extração de minerais não- } \\
\text { metálicos }\end{array}$ & 8.393 & 0,03 & 25.088 & 0,04 & 198,93 \\
\hline $\begin{array}{l}\text { Fabricação de produtos } \\
\text { alimentícios, bebidas... }\end{array}$ & 4.030 .116 & 15,79 & 10.068 .154 & 17,37 & 149,82 \\
\hline $\begin{array}{l}\text { Fabricação de produtos têxteis, } \\
\text { vest., couro e ... }\end{array}$ & 135.132 & 0,53 & 226.638 & 0,39 & 67,72 \\
\hline $\begin{array}{l}\text { Impressão e reprodução de } \\
\text { gravações }\end{array}$ & 944.674 & 3,70 & 909.596 & 1,57 & $-3,71$ \\
\hline $\begin{array}{l}\text { Fabricação de produtos de } \\
\text { madeira, celulose... }\end{array}$ & 1.908 .557 & 7,48 & 1.464 .291 & 2,53 & $-23,28$ \\
\hline $\begin{array}{l}\text { Fabricação de prod. } \\
\text { petroquímicos e farmacêuticos }\end{array}$ & 1.857 .510 & 7,28 & 874.151 & 1,51 & $-52,94$ \\
\hline $\begin{array}{l}\text { Fabricção de prod. de borracha } \\
\text { e de mat. plástico }\end{array}$ & 828.671 & 3,25 & 1.099 .278 & 1,90 & 32,66 \\
\hline $\begin{array}{l}\text { Fabricação de produtos de } \\
\text { miner. não-metálicos }\end{array}$ & 308.853 & 1,21 & 1.779 .757 & 3,07 & 476,25 \\
\hline $\begin{array}{l}\text { Metalurgia e fabricação de } \\
\text { produtos de metal }\end{array}$ & 1.945 .314 & 7,62 & 3.399 .948 & 5,86 & 74,78 \\
\hline $\begin{array}{l}\text { Fabricação de produtos } \\
\text { eletrôn., informática... }\end{array}$ & 8.578 .566 & 33,61 & 9.348 .599 & 16,13 & 8,98 \\
\hline $\begin{array}{l}\text { Fabricação de máquinas, } \\
\text { equipam. e manutenção }\end{array}$ & 1.027 .546 & 4,03 & 1.204 .285 & 2,08 & 17,20 \\
\hline $\begin{array}{l}\text { Fabricação de veículos autom., } \\
\text { reboq. e carroc. }\end{array}$ & 61.654 & 0,24 & 199.636 & 0,34 & 223,80 \\
\hline $\begin{array}{l}\text { Fabricação de outros equipam. } \\
\text { de transporte }\end{array}$ & 1.520 .331 & 5,96 & 4.692 .564 & 8,09 & 208,65 \\
\hline $\begin{array}{l}\text { Fabricação de móveis e de } \\
\text { produtos diversos }\end{array}$ & 468.461 & 1,84 & 1.249 .282 & 2,15 & 166,68 \\
\hline
\end{tabular}

Nota: Valores em R\$1.000, deflacionados para 2010 pelo IGP-DI.

Fonte: IBGE, Pesquisa Industrial Anual - Empresa, 1996 e 2010. Elaboração dos autores.

O crescimento regional do VTI vinculado à fabricação de produtos alimentícios, bebidas e produtos do fumo (149,82\%) situou-se acima da média nacional, ampliando sua participação no VTI do Norte de $15,79 \%$ para $17,37 \%$.

Novos Cadernos NAEA • v. 15 n. $2 \cdot$ p. 111-141 • dez. 2012 
Em termos absolutos, o segmento foi responsável pela maior geração de emprego na região (35.477), no período, elevando sua participação de 16,45\%, em 1996, para 21,50\%, em 2010. Em termos nacionais, tal comportamento reflete o crescimento no aumento do consumo de bens salário no período. Em termos regionais, esse resultado vincula-se, em alguma medida, ao regime de incentivos fiscais que beneficia a indústria de bebidas no estado do Amazonas. Isto porque as grandes empresas que fabricam concentrados (insumo básico para produção de refrigerantes) estão instaladas no Polo Industrial de Manaus (PIM).

Cresceu, ainda, a fabricação de outros equipamentos de transporte, que agrega a produção de motocicletas, motonetas, bicicletas, quadriciclos - também baseada no PIM e que é a principal responsável pela expansão da categoria (FREITAS, 2009). Nela, houve variação relativa do VTI de mais de $200 \%$, entre 1996 e 2010 (Gráfico 1), aumento de 31 unidades industriais e multiplicação por quatro do número de pessoal ocupado que passou de 4.718 para 21.225.

Gráfico 1 - Participação relativa no VTI da região Norte, categorias de indústria selecionadas (1996-2010).

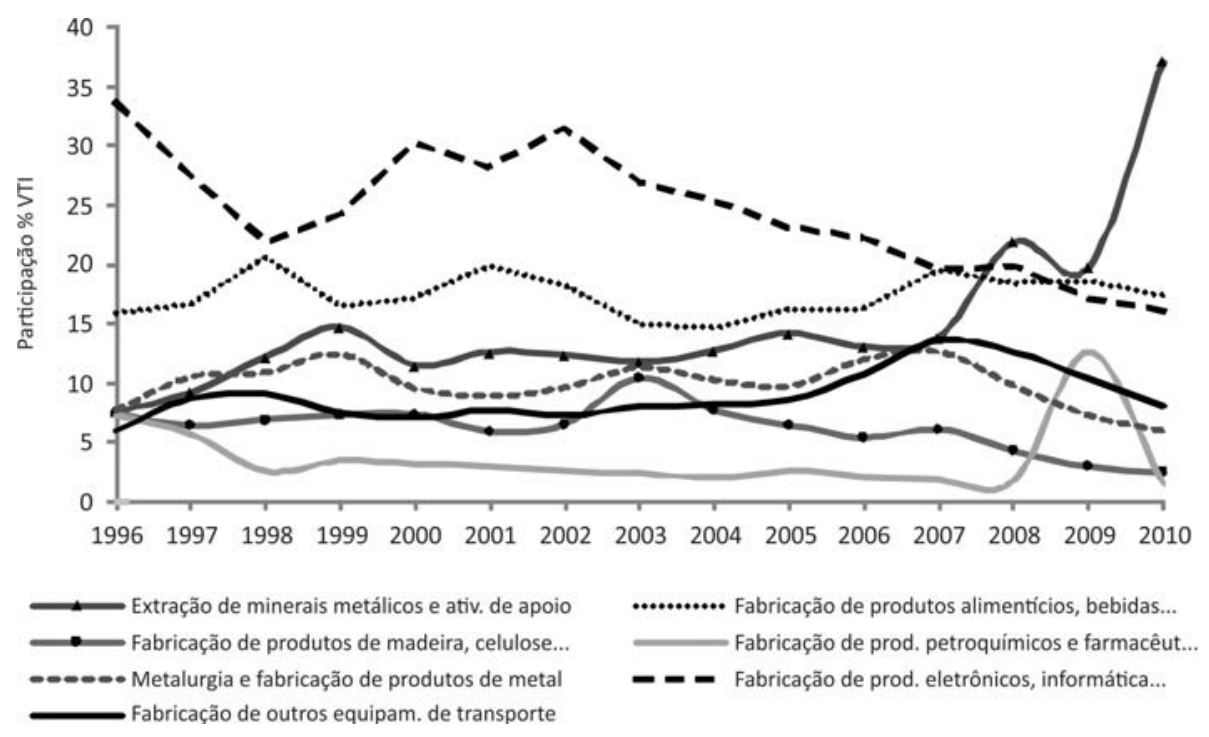

Fonte: IBGE, Pesquisa Industrial Anual - Empresa, 1996 a 2010. Elaboração dos autores.

Pode-se afirmar, portanto, que em relação à dinâmica da indústria da região há dois movimentos aparentemente distintos. Um representado pelo crescimento acelerado da indústria extrativa mineral no estado do Pará, resultando na ampliação da especialização relativa da indústria no estado; o outro pela 
redução, em termos relativos, da indústria de transformação e pela ampliação da sua concentração espacial no PIM.

\section{INDICADORES DE COMPETITIVIDADE REGIONAL}

Como foi evidenciado, o grande crescimento do VTI no estado do Pará teve vinculação direta com a expansão da indústria extrativa; já no Amazonas, a expansão do VTI decorreu, principalmente, de algumas categorias da indústria de transformação. Segundo Sousa (2002), em análises sobre os padrões de especialização de um estado em determinadas categorias de indústria, o que geralmente não é explicado são as características que configuram tais categorias, Todavia, isto pode ser explicitado através de uma análise temporal de indicadores de características da especialização industrial no estado. Assim, é possível explicar se um estado aumentou a participação em categorias de indústrias cujos valores dos indicadores de dadas características são maiores. Ao avaliar as características que influenciam na composição da estrutura industrial de cada estado, utilizou-se o cálculo do Viés Característico da Indústria (VCI). Dessa forma, para explicitar as diferenciações entre estes padrões de expansão da indústria, a seguir é avaliado, para cada um dos dois setores da indústria (extrativa e de transformação), o peso de quatro características: intensidade de remuneração média, participação do trabalho, economia de escala e intensidade de intermediários.

O VCI para o conjunto da indústria extrativa no estado do Pará, entre 1996 e 2010, indica que este setor tem como vieses explicativos da sua lógica de inserção regional a baixíssima intensidade de consumo de produtos intermediários, a reduzidíssima parcela do valor adicionado capturada pelo trabalho e a queda da remuneração média dos trabalhadores. Para este setor industrial, a economia de escala é também uma característica relevante. Mesmo sofrendo, no período, oscilações para menor, a tendência é que esta característica amplie sua relevância no futuro em função da entrada em operação de grandes estruturas de extração de minerais metálicos em implantação (Gráfico 2). 
Gráfico 2 - Viés característico da indústria extrativa do estado do Pará (19962010).

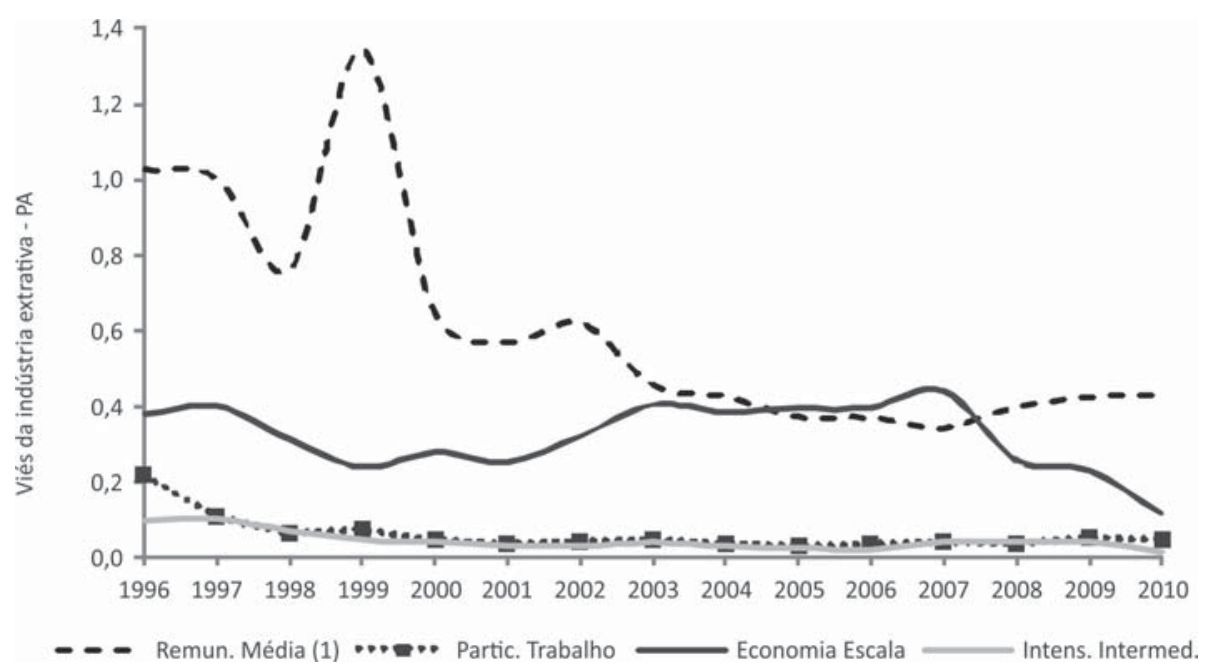

(1) Valores convertidos para número decimal.

(2) A remuneração média de 2010 foi estimada pelos autores.

Fonte: IBGE, Pesquisa Indústria Anual - Empresa, 1996-2010. Elaboração dos autores.

A remuneração média da indústria de transformação do Amazonas é superada pela da indústria extrativa do Pará, mesmo quando se considera a trajetória de queda desta, que foi interrompida em 2007 (Gráfico 2). Monteiro e Cruz (2012) demonstram que a remuneração média mais elevada da indústria extrativa, em termos regionais, guarda relação com o maior nível de produtividade, rentabilidade e nível de capacitação tecnológica deste setor em relação àquele. Ao inferirem o nível de capacitação tecnológica - expresso pela razão entre o número de empregados de nível superior e o total de empregados - indicam que, em 1996, o percentual de empregados de nível superior na indústria extrativa era $2,6 \%$, e que, em 2010 , este percentual subiu para $13 \%$.

No mesmo estudo, ao inferirem a competitividade de categorias da indústria na região Norte por meio de indicadores do nível de capacitação (porte médio e capacitação tecnológica), de eficiência (produtividade e estrutura de custo) e de desempenho (capacidade de agregação de valor, rentabilidade e markup); e, ao compararem os indicadores da extração de minerais metálicos e atividades de apoio com as demais categorias da indústria, indicaram que: a) o porte médio e a capacitação tecnológica daquela categoria de indústria são os maiores e que ela concentra, em termos proporcionais, o maior número de empregados de nível 
superior; b) o maior nível da produtividade relativa do trabalho lhe é atribuído e nela se registra a existência de forte associação entre salários altos, maior nível de escolaridade e elevada produtividade; c) as margens de custo da matéria-prima e do trabalho dessa categoria são as menores da região e muito inferiores às do Brasil; d) os indicadores de rentabilidade a apontam como a categoria de indústria com maior capacidade de gerar excedentes através da produção e como aquela que apresenta maior efetiva retenção de lucros; e e) o markup mais elevado foi registrado por ela, evidenciando características de estrutura oligopolizada nessa categoria (MONTEIRO, CRUZ, 2012).

São constatações que corroboram os vieses característicos do setor indústria extrativa identificados para o Pará (Gráfico 2) e que justificam a superioridade do crescimento da extração de minerais metálicos e das atividades de apoio na composição do VTI do Norte em relação às demais (Gráfico 1).

Já no Amazonas, na indústria de transformação verifica-se que a economia de escala e a intensidade de consumo de produtos intermediários representam as características mais relevantes desse setor industrial. A remuneração média é viés que, após queda entre 1999 e 2005, vem registrando sinais de recuperação; enquanto a participação do trabalho nos ganhos permanece estável (Gráfico 3). São, portanto, vieses característicos bastante diferentes dos verificados em relação à indústria extrativa no Pará.

Gráfico 3 - Viés característico da indústria de transformação do estado do Amazonas (1996-2010).

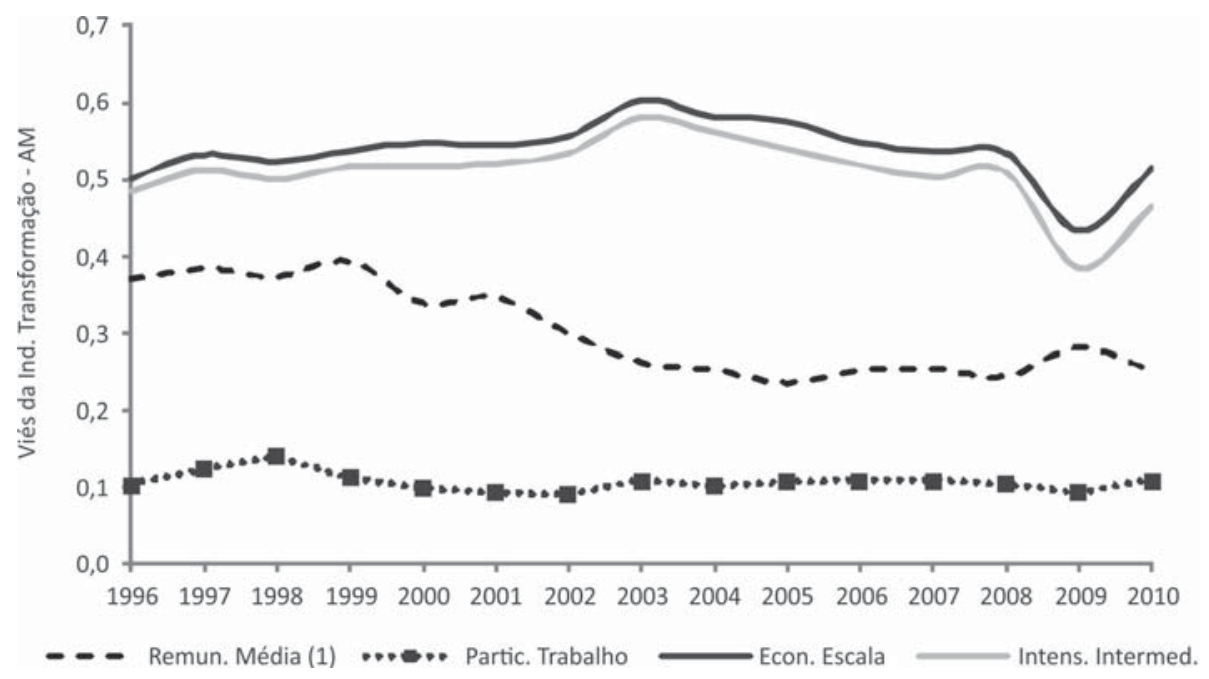

(1) Valores convertidos para número decimal.

Fonte: IBGE, Pesquisa Indústria Anual - Empresa, 1996-2010. Elaboração dos autores.

Novos Cadernos NAEA •v. 15 n. $2 \cdot$ p. 111-141 • dez. 2012 
Como confirmação destes vieses, a partir de 2003, a economia amazonense tem atraído unidades industriais para os quais economia de escala, eficiência produtiva relativamente alta e de especialização e qualificação da força de trabalho são características decisivas. A melhora nos índices de economia de escala, de intensidade de intermediários e da remuneração média também deverão se refletir em menores custos de produção.

A economia de escala e a intensidade de intermediários que se destacam como vieses característicos da indústria de transformação no Amazonas, por um lado, guardam coerência com o fato de haver grande concentração espacial de unidades industriais no Parque Industrial de Manaus, a maior da região Norte (OLIVEIRA JÚNIOR, MACHADO, 2009), por outro, podem ser indícios de que as dinâmicas que fundamentam o crescimento da indústria no Amazonas impulsionam a formação de um tipo de aglomerado urbano que, segundo Storper e Venables (2005), enseja o surgimento de externalidades positivas capazes de impulsionar rendimentos crescentes e processos de desenvolvimento duradouros.

Já a grande expansão da indústria extrativa, mesmo fortalecendo aglomerações urbanas regionais (MONTEIRO, COELHO, BARBOSA, 2012), ao ter como vieses característicos a baixíssima intensidade do consumo de intermediários, a redução do valor adicionado capturado pelo trabalho e a queda da remuneração média da força de trabalho, pode ser indicativo da restrição de este setor industrial contribuir decisivamente para o estabelecimento regional do que Krugman (1995) indica como sendo mecanismo dinâmico do autorreforço endógeno formado pelas economias externas propagadas por redes mercantis e não mercantis criadas pela aglomeração industrial, tendo limitação de amalgamar relações que impulsionem a construção de arranjos produtivos capazes de alimentarem localmente dinâmicas que favoreçam o estabelecimento de processos de desenvolvimento socialmente enraizados. Os vieses captados apontam, por conseguinte, que este setor impulsiona dinâmicas e processos de valorização facilmente reversíveis (BECKER, 2005, p. 409), mas irreversíveis do ponto de vista energético e material (MONTEIRO, 2003, p. 145).

\subsection{A COMPETITIVIDADE RELATIVA DA INDÚSTRIA NA REGIÃO NORTE}

Ao se avaliar a competitividade de categorias da indústria regional diante da nacional, mais uma vez, ganha relevo a extração de minerais metálicos que teve o melhor desempenho dos indicadores de custo relativo dentre todas as demais 
indústrias. Tal superioridade no desempenho foi inferida por meio do ICUR. Como, anteriormente, indicado, o ICUR revela a vantagem (ou desvantagem) de uma região resultante de menores custos da mão de obra, de maior produtividade ou da combinação favorável desses dois fatores. O valor do índice maior que a unidade revela que os custos do trabalho superam os ganhos de produtividade e vice-versa. A avaliação da competitividade da indústria regional diante da nacional indicou que a extração de minerais metálicos ampliou sua competitividade potencial relativa, visto que o ICUR, situado abaixo da unidade, variou de 0,67 para 0,54, uma oscilação favorável de 19,63\% no período (Gráfico 4). Essa vantagem é resultante da elevada produtividade do trabalho que se situava $91,23 \%$ acima da média do país em 1996, sendo ampliada para 113,41\% em 2010.

Gráfico 4 - Índice de Custo Relativo (ICUR) de categorias de indústrias selecionadas, estado do Pará (1996-2010).

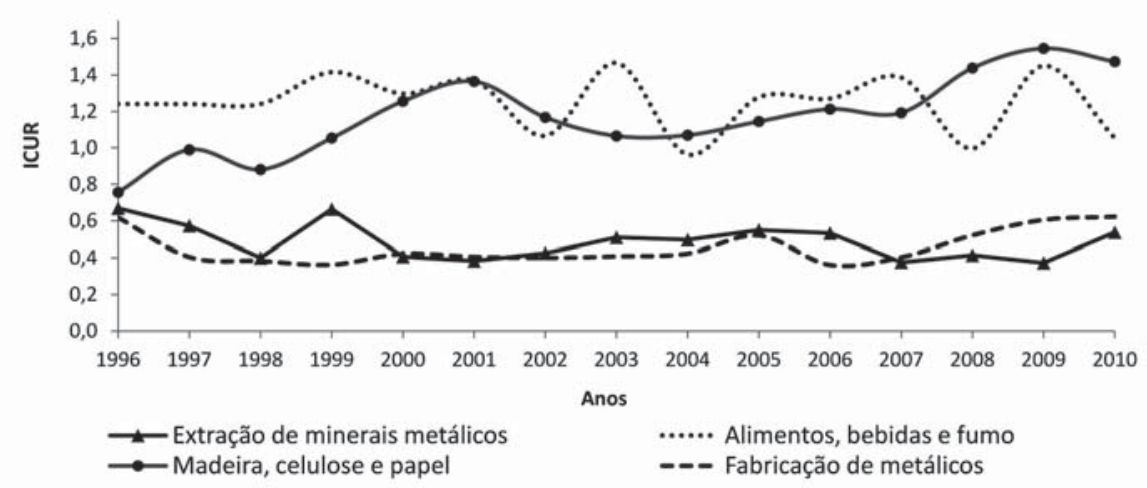

Fonte: IBGE, Pesquisa Indústria Anual - Empresa, 1996-2010. Elaboração dos autores.

$\mathrm{Na}$ indústria de transformação, a metalurgia e fabricação de produtos de metal é a única categoria de indústria com vantagem competitividade potencial superior à indústria nacional, mantendo um custo relativo abaixo da unidade e variando apenas 0,6\% no período (Gráfico 4). Em 1996, a produtividade média e a remuneração média dessa categoria situavam-se em torno de 157,8\% e 59,4\% acima da média da indústria nacional, respectivamente. Em 2010, esses índices oscilaram para $83,7 \%$ e $14,2 \%$, respectivamente, mas a produtividade média ainda se manteve muito acima da média nacional, e, mesmo com a remuneração do trabalho tendo se aproximado da média nacional, esta categoria manteve sua competitividade potencial relativa. 
Duas categorias de indústria tiveram sua competitividade relativa reduzida. A fabricação de produtos de madeira, celulose e papel teve seu índice oscilando de 0,76 para 1,47, deteriorando-se, portanto, 94,8\% no período. O ICUR da fabricação de outros equipamentos de transporte deteriorou de 0,63 para 1,55, em 2009, porém, em 2010, o índice recuou para 0,64, indicando uma possível recuperação (Gráfico 4).

No caso da fabricação de produtos de madeira, celulose e papel, apesar de a remuneração da força de trabalho ser menor que a média nacional, a produtividade sempre foi muito baixa, situando-se, em 2010, 61,7\% abaixo da média do país.

No caso da fabricação de outros equipamentos de transporte, o fator determinante para a perda da competitividade potencial relativa foi a queda da produtividade, uma vez que a remuneração do trabalho esteve sempre abaixo da média da indústria nacional. No início da série a produtividade dessa categoria era $17,1 \%$ superior à média nacional, recuando para patamar de $33 \%$ abaixo da média do país, variação negativa de $37 \%$ contra uma variação positiva de $10 \%$ da produtividade dessa categoria de indústria.

Ao longo da série, três categorias de indústria, no Pará, registraram ICUR acima da unidade: fabricação de produtos alimentícios, bebidas e produtos do fumo; fabricação de produtos petroquímicos e farmacêuticos; e fabricação de máquinas, equipamentos e manutenção. A produtividade e a remuneração média dessas categorias, situadas abaixo da média do país, refletem custos relativos maiores e, portanto, menor competitividade potencial.

Para o estado do Amazonas, quatro categorias ${ }^{1}$ de indústria de transformação apresentaram competitividade potencial relativa no período avaliado: fabricação de produtos alimentícios, bebidas e produtos do fumo; metalurgia e fabricação de produtos de metal; fabricação de produtos petroquímicos e farmacêuticos; e a fabricação de outros equipamentos de transporte. Em comum, essas categorias detêm uma produtividade média muito acima da observada para as respectivas atividades da indústria do país, e o custo unitário da mão de obra gira em torno da média nacional. Resultado assegurando por redução de custos de produção viabilizado por meio de política federal de renúncia fiscal.

Em razão do registro de informação apenas para os últimos quatro anos da série, a análise do ICUR para atividade de extração de minerais metálicos ficou comprometida, sendo suprimida do gráfico. 
A fabricação de produtos alimentícios, bebidas e produtos do fumo destaca-se por ter ampliado sua competitividade potencial relativa, o índice alcançou 0,24, em 1996, e melhorou em 2010, atingindo 0,16, registrando, assim, oscilação de 30,4\% (Gráfico 5). Contribuiu, para o desempenho favorável da categoria, a elevada produtividade que no início da série era cinco vezes maior que a média nacional e se ampliou para seis vezes no final da série. Além disso, a remuneração do trabalho recuou 39,6\% no período, mantendo-se abaixo da média dessa categoria de indústria, no país.

Gráfico 5 - Índice de Custo Relativo (ICUR) de categorias de indústria selecionadas, estado do Amazonas (1996-2010).

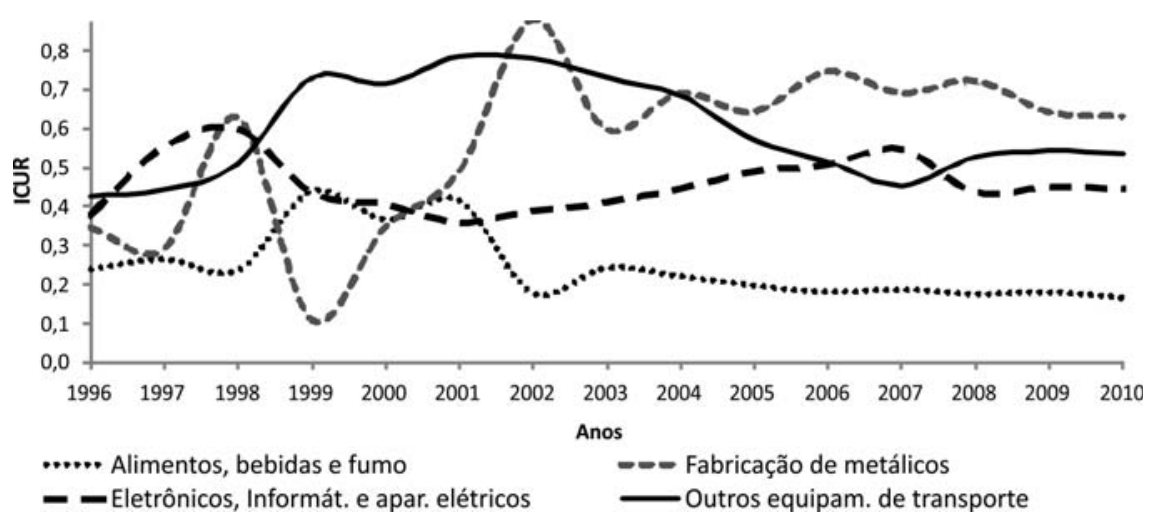

Fonte: IBGE, Pesquisa Indústria Anual - Empresa, 1996-2010. Elaboração dos autores.

No Amazonas, entre 2003 e 2008, a indústria petroquímica registrou ICUR acima da unidade, recuperando sua competitividade potencial relativa nos anos seguintes. A fabricação de produtos de madeira, celulose e papel, por sua vez, apresentou índices maiores que a unidade ao longo da série, refletindo sua desvantagem em relação à indústria nacional, o que decorre principalmente da baixa produtividade do trabalho (Gráfico 5).

A fabricação de produtos eletrônicos, informática e aparelhos elétricos, assim como a fabricação de outros equipamentos de transporte, registrou perda de competitividade ao longo da série com os índices aumentando de 0,38 para 0,44 e de 0,42 para 0,53, respectivamente (Gráfico 5). A explicação está na queda, em termos regionais, da produtividade do trabalho dessas categorias na ordem de 30,1\% e $31,32 \%$, contra variações de negativa de $23,1 \%$ e positiva de $10 \%$, respectivamente, verificadas para as mesmas categorias de indústria em termos nacionais. 
Em síntese, o ICUR aponta competitividade potencial relativa da extração de minerais metálicos; da metalurgia e fabricação de produtos de metal; da fabricação de produtos alimentícios, bebidas e produtos do fumo; da fabricação de máquinas, equipamentos e eletroeletrônicos; além da fabricação de outros equipamentos de transporte, com os dois últimos apresentando tendência de perda de competitividade. Enfrenta maior desvantagem em termos de desempenho competitivo, com ICUR acima da unidade, a fabricação de produtos petroquímicos e farmacêuticos, além da fabricação de produtos de madeira, celulose e papel. Ambas possuem baixa produtividade, pouca capacidade de agregação de valor, elevadas margens de custos e baixa rentabilidade do capital associadas à dificuldade das unidades industriais em gerar excedente pela produção.

\section{COMENTÁRIOS FINAIS}

Entre 1996 e 2010, a expansão do valor adicionado industrial na região Norte vinculou-se ao crescimento muito acelerado da indústria extrativa mineral, basicamente a extração de minerais metálicos e atividades de apoio, que teve seu valor multiplicado por dez; e à ampliação, em ritmo bem mais moderado, de algumas categorias da indústria de transformação, em especial a fabricação de produtos alimentícios, bebidas e produtos do fumo (149,82\%), a metalurgia e fabricação de produtos de metal $(74,78 \%)$, a fabricação de outros equipamentos de transporte $(208,65 \%)$.

Ao se apreender os fundamentos desta expansão, demonstrou-se que a indústria extrativa mineral é a que, destacadamente, apresenta os melhores indicadores de competitividade da região, todavia, os viesses característicos desse setor (a baixíssima intensidade do consumo de intermediários, a redução do valor adicionado capturado pelo trabalho e a queda da remuneração média da força de trabalho) podem ser indicativos de limitações de esta indústria impulsionar o surgimento de arranjos produtivos capazes de alimentarem localmente dinâmicas que favoreçam o estabelecimento de processos de desenvolvimento socialmente enraizados. Por outro lado, evidenciou-se que a economia de escala e a intensidade de intermediários são vieses característicos da indústria de transformação no Amazonas, guardando coerência com o padrão de concentração espacial das unidades industriais no estado. Por sua vez, tais características podem ser indícios de que as dinâmicas que fundamentam o crescimento do valor adicionado 
industrial naquele estado estimulam o surgimento de externalidades positivas capazes de impulsionar rendimentos crescentes e processos de desenvolvimento duradouros, distinções que, evidentemente, têm implicações diretas sobre processos de desenvolvimento regional.

Os indícios aqui identificados são significativos e relevantes, todavia, requerem, como sugere Costa (2012, p. 8), tratamento teórico e metodológico mais sofisticado que permita: a) superar a delimitação, extremamente abstrata, de estados, viabilizando a identificação de espaços socialmente construídos e superação da forma homogênea como foram agrupadas as categorias de indústria, viabilizando o tratamento dos atores em sua diversidade. b) observar as relações desses atores em organismos, conferindo-lhes configuração especifica, cuja interação conformaria as economias locais; c) verificar as indicações de produtividade crescente dessas economias locais na integridade das configurações urbana/rural, por uma parte, e local/extralocal, por outra.

\section{REFERÊNCIAS}

AZEVEDO, P. F.; TONETO JUNIOR, R. Relocalização do emprego industrial formal no Brasil: na década de 90. Pesquisa e Planejamento Econômico, Rio de Janeiro, v. 31, n. 1, p. 153-186, abr. 2001.

BECKER, B. K. Dinâmica urbana na Amazônia. In: DINIZ, C. C.; LEMOS, M. B. (Org.). Economia e território. Belo Horizonte: Ed. UFMG, p. 401-428, 2005.

BUNKER, S. G. Joint ventures em ambientes frágeis: $O$ caso do alumínio na Amazônia. Novos Cadernos NAEA, Belém, v. 3, n. 1, p. 5-46, jun. 2000.

BUNKER, S. G. Os fatores espaciais e materiais da produção e os mercados globais. Novos Cadernos NAEA, Belém, v. 7, n. 2, p. 67-108, dez. 2004.

COELHO, M. C. N.; MONTEIRO, M. A. As economias extrativas e o subdesenvolvimento da Amazônia brasileira: contribuições do Prof. Stephen Bunker. Novos Cadernos NAEA, Belém, v. 8, n. 1, p. 5-17, jun. 2005. 
COUTINHO, L.; FERRAZ, J. C. Estudo da competitividade da indústria brasileira. Campinas, SP: Papirus, 1994.

COSTA, F. A. Decodificando economias locais: análise da estrutura e dinâmica do sudeste paraense utilizando CSa*. Texto para Discussão, Brasília: IPEA, v. 1723, p. 1-57, 2012.

DINIZ, C. C. Desenvolvimento poligonal no Brasil: nem desconcentração nem contínua polarização. Revista Nova Economia, Belo Horizonte, v. 31, n. 11, p. 35-64, set. 1993.

DUNCAN, O. D.; DUNCAN, B. A. A methodological analysis of segregation indexes. American Sociological Review, v. 20, n. 2, p. 210 $217,1955$.

FREITAS, R. M. Pujança econômica e evolução recente na indústria de duas rodas. T\&C Amazônia, Manaus, Ano 7, n. 17, 2009.

GARCIA, E. Zona Franca de Manaus: história, conquistas e desafios. Manaus: Norma/SUFRAMA, 2004.

GONÇALVES, E. et al. Competitividade industrial de Minas Gerais no período 1985-2000: um enfoque econométrico. Nova Economia, Belo Horizonte, v. 13, n. 2, p. 81-108, jul/dez. 2003.

HADDAD, P. R. (Org.). Medidas de localização e de especialização. In: . Economia regional: teorias e métodos de análise. Fortaleza: Banco do Nordeste do Brasil, p. 225-247, 1989.

HOOVER, E. M.; GIARRATANI, F. An introduction to regional economics. In: Web book of regional science. Morgantown Regional Research Institute - West Virginia University, 1984. Disponível em: http:/ / www.rri.wvu.edu/WebBook/Giarratani/main.htm>Acesso: 03 fev. 2012.

IBGE. Pesquisa Industrial Anual - Empresa. Rio de Janeiro: IBGE, 2004. 85 p. (Série relatórios metodológicos, v. 26).

IBGE. Pesquisa Industrial Anual - PIA (1996 - 2010): empresa. Disponível em< http://www.ibge.gov.br/home/download/estatistica. shtm> Acesso em: 30 jun. 2012. 
IBGE. Comissão Nacional de Classificação - CONCLA. Disponível em: $<\quad$ http://concla.ibge.gov.br/classificacoes/correspondencias/ atividades-economicas> Acesso em: 30 jul. 2012.

ISARD, W. Methods of regional analysis. Cambridge-MA: MIT Press, 1960.

KRUGMAN, P. Development, geography and economic theory. Cambridge, Massachusetts London, England: The MIT Press, 1995.

LEMOS, M. B.; SANTOS, F.; CROCCO, M. Condicionantes territoriais das aglomerações industriais sob ambientes periféricos. In: DINIZ, C. C.; LEMOS, M. B. (Org.). Economia e território. Belo Horizonte: Ed. UFMG, p. 171-205, 2005.

MIDELFART-KNARVIK, K. H. et al. The location of European industry. European Economy - Economy Paper, n. 142, Brussels, 2000.

MONTEIRO, M. A. Mineração industrial na Amazônia e suas implicações para o desenvolvimento regional. Novos Cadernos NAEA, Belém, v. 8, n. 1, p. 141-187, jun. 2005.

MONTEIRO, M. A. A ICOMI no Amapá: meio século de exploração mineral.

Novos Cadernos NAEA, Belém, v. 6, n. 1, p. 113-168, dez. 2003.

MONTEIRO, M. A.; CRUZ, A. G. A superioridade do desempenho da indústria extrativa mineral face a de transformação na região norte: 1996-2010. Paper do NAEA, Belém, n. 291, 2012.

MONTEIRO, M. A.; COELHO, M. C. N.; BARBOSA, E. J. S. Fronteira, corredores de exportação e rede urbana na Amazônia oriental brasileira. GEOgraphia, Rio de Janeiro, v. 13, n. 26, p. 37-65, 2011.

OLIVEIRA JUNIOR, A. R. et al. Metamorfoses do modelo Zona Franca de Manaus: desafios à pesquisa e ao planejamento do desenvolvimento regional. In: SCHERER, E.; OLIVEIRA, J. A. (Org.). Amazônia: políticas públicas e diversidade cultural. Manaus: Garamond Universitária, p. 39-59, 2006.

OLIVEIRA JUNIOR, A. R.; MACHADO, J. A. C. Pólo Industrial de Manaus e sua Dinâmica. In: RIVAS, A.; MOTA, J. H.; MACHADO, J. A. C. (Org.). Instrumentos econômicos para a proteção da Amazônia: a experiência do pólo industrial de Manaus. Curitiba: Editora CRV, p. 31-51, 2009. 
POSSAS, M. L. Estrutura industrial brasileira: base produtiva e liderança dos mercados. 1977. 181 f. Dissertação (Mestrado em Economia) - Departamento de Economia e Planejamento Econômico, Campinas, SP, 1977.

ROSSI, J. L.; FERREIRA, P. C. Evolução da produtividade industrial brasileira e abertura comercial. Pesquisa e Planejamento Econômico, Rio de Janeiro, v. 29, p 1-36, 1999.

SABOIA, J. L. Descentralização industrial no Brasil na década de noventa: um processo dinâmico e diferenciado regionalmente. Nova Economia, Belo Horizonte, v. 11, n. 2, p. 85-122, dez. 2001.

SALM, C.; SABOIA, J. L.; CARVALHO, P. G. M. Produtividade na indústria brasileira: questões metodológicas e novas evidências empíricas. Pesquisa e Planejamento Econômico, Rio de Janeiro, v. 27, n. 2, p. 377 396, ago. 1997.

SILVA, A. B. O.; ALVES, J. D. Análise regional da competitividade da indústria mineira utilizando os microdados da PIA, 1996-2006. Nova Economia, Belo Horizonte, v. 20, n. 2, p. 219-252, maio/ago. 2010.

SILVA, M. A. R. Royalties da mineração: instrumentos de produção do desenvolvimento sustentável de regiões mineradoras na Amazônia Oriental?. Novos Cadernos NAEA, Belém, v. 1, n. 2, p. 115-130, 1998.

SOUSA, F. L. A Localização da Indústria de transformação brasileira nas últimas três décadas. 2002. 130 f. Dissertação (Mestrado), EPGE/ FGV, Rio de Janeiro, 2002.

STORPER, M.; VENABLES, A. J. O burburinho: a força econômica da cidade. In: DINIZ, C. C.; LEMOS, M. B. (Org.). Economia e território. Belo Horizonte: Ed. UFMG, p. 21-56, 2005.

Texto submetido à Revista em 28.01.2012

Aceito para publicação em 12.06.2012

Os autores agradecem o apoio do $\mathrm{CNPq}$, por meio do projeto de pesquisa Processo no 482585/2012-9, bem como a concessão de bolsa PIBIC para Hugo Ernandes Saldanha Correia. 


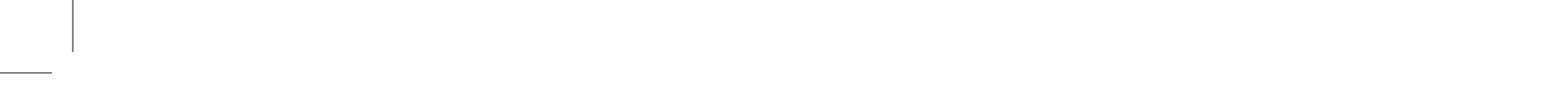

